\title{
SIMULAÇÃO DO EFEITO DE USO DA TERRA NA ATENUAÇÃO DA ENERGIA CINÉTICA DA CHUVA SOBRE UMA BACIA HIDROGRÁFICA NO SUDOESTE DE GOIÁS
}

\author{
LIMA, Halan Faria - halanfl@hotmail.com \\ Instituto Federal de Goiás / IFG \\ ASSUNÇÃO, Hildeu Ferreira da - hildeu@yahoo.com.br \\ Universidade Federal de Goiás / UFG \\ SCOPEL, Iraci - iraciscopel@gmail.com \\ Universidade Federal de Goiás / UFG
}

\begin{abstract}
RESUMO: As simulações do impacto cinético das chuvas sobre o solo em bacias hidrográficas são importantes para planejamento agronômico, ambiental e regional. Objetivou-se, com o presente trabalho, simular o efeito atenuante da cobertura vegetal na redução do impacto cinético das precipitações na bacia do Ribeirão Paraíso. Para isso utilizou-se aspectos topográficos e dados das propriedades pluviométricas de diferentes períodos de cultivo observados durante 12 meses, para simular a energia cinética das chuvas sobre as encostas. Os resultados mostraram que o pluviômetro de PVC de 163 $\mathrm{cm}^{2}$, cujos dados foram utilizados para o presente estudo, é compatível com o pluviômetro padrão do INMET. As análises dos resultados mostraram que a maioria das chuvas vem de sudeste, seguida por chuvas vindas do Sul e variam com os meses observados. A declividade e orientação das vertentes dentro da bacia favoreceram a simulação no sentido de evidenciar o impacto das chuvas. As maiores precipitações ocorreram em fevereiro de 2012 e janeiro de 2013, as maiores atenuações de impactos ocorreram durante os meses de abril de 2012 e janeiro de 2013, principalmente sobre as vertentes contrárias à direção predominante das chuvas e com declividade aproximada à da inclinação das chuvas. Foi observado também que o efeito atenuante da cobertura do solo mostrou resultados acentuados, ou seja, o solo com cobertura sofreu menor impacto, em relação à cobertura e época de cultivo e isso leva a concluir que a simulação adotada chegou a resultados relevantes uma vez que foi possível evidenciar onde ocorrem as maiores reduções de impactos cinéticos da chuva.
\end{abstract}

PALAVRAS-CHAVES: pluviômetros vetoriais, declividade, orientação de vertentes, redução do impacto de gotas de chuva.

SIMULATION OF LAND USE EFFECT IN THE ATTENUATION OF THE RAINFALL KINETIC ENERGY ON A HYDROGRAPHIC BASIN IN SOUTHWESTERN GOIÁS

ABSTRACT: Simulations of rain kinetic impacts on soil in watershed are important for agronomic, environmental and regional planning. We aim, with this study, to simulate the attenuating effect of cover vegetation in reducing the rain kinetic impact in the Ribeirão Paraíso watershed. For this, we used topographic aspects and pluviometric properties data of different cultivation periods of 12 months observations to simulate the rain kinetic energy on the slopes. The results showed that the $163-\mathrm{cm}^{2}$ PVC pluviometer, whose data were used for this study, is compatible with the INMET standard pluviometer. Analysis of the results showed that most of the rainfall comes from southeast, followed by rainfall from south and it varies with observed months. The slope and orientation of the slopes within the watershed favored the simulation in order to show the impact of the rains. The largest rainfall occurred in February 2012 and January 2013, the greatest mitigation of impacts occurred during April 2012 and January 2013, mainly on the slopes opposite to the rains predominant direction and with a resembling slope to the rain inclination. It was also observed that the soil cover attenuation effect showed marked results, in other words, the covered soil suffered less impact, in relation to the cover and growing season, and this leads to the conclusion that the simulation adopted reached relevant results 
once it was possible to show where the greatest reductions of kinetic rainfall impacts occur.

KEYWORDS: vector gauges, slope, orientation of the aspects, reducing.

\section{INTRODUÇÃO}

O município de Jataí, situado no sudoeste de Goiás, é caracterizado pela diversificação de atividades agropecuárias e agroindustriais, devido às condições edáficas e climáticas favoráveis. Concentradas em bacias hidrográficas, essas atividades são limitadas pela topografia do terreno, pelos solos inaptos e pela rede de drenagem, cuja área destinada às reservas legais e permanentes totaliza aproximadamente 107.000 hectares (IMB, 2006).

As atividades agrícola e pecuária são importantes para o crescimento econômico do município e trazem preocupação acerca do uso e ocupação do solo e recursos hídricos. De forma que, mesmo com a adoção de técnicas de conservação dos solos e uso eficiente da água, estes recursos naturais estão sujeitos à acelerada degradação, em função da ação erosiva das chuvas, principalmente nas vertentes, nas periferias urbanas e nas margens da rede viária, as quais são áreas que sofrem forte influência antrópica.

O município de Jataí possui várias bacias hidrográficas relevantes, entre elas a do Rio Claro e a do Rio Doce. Do ponto de vista da extensão, dentre as sub-bacias, destaca-se a bacia do Ribeirão Paraíso, que possui maior distinção topográfica e uso do solo diversificado, apresentando áreas com soja, milho, cana-de-açúcar e reservas (matas ciliares e Cerrado).

Segundo Nimer (1989), o Sudoeste do estado de Goiás está sujeito aos sistemas de correntes perturbadas de oeste, trazidos pelas linhas de instabilidade tropicais de oeste e noroeste, que acarretam chuvas e trovoadas, entre o final da primavera e o início do outono. E aos sistemas de correntes perturbadas do Sul, com a invasão do anticiclone polar, que provoca chuvas frontais e pré-frontais durante o verão.

As chuvas nesta região podem totalizar, em média, $1630 \mathrm{~mm}$ anuais (INMET, 2013). A ação de tais sistemas, além de favorecer as atividades agropecuárias de forma geral, também pode intensificar o processo erosivo nos solos. Para regiões cujo uso desse recurso é mais intensivo, como o CentroOeste do Brasil, onde é possível obter duas safras anuais, a intensidade pluviométrica torna-se preocupante, principalmente nas situações em que a chuva atinge o solo desprotegido.

Neste sentido, estimar a energia cinética das chuvas e simular o efeito da cobertura vegetal como fator atenuante do impacto pluviométrico em bacias hidrográficas torna-se relevante. Assim, a utilização de modelos matemáticos, que são procedimentos para simulação de determinadas condições e permitem predizer a resposta às ações naturais e/ou antrópica em um dado meio, mostrase como ferramenta bastante importante para o manejo de bacias. Sendo ferramentas rápidas e de relativamente baixo custo para simular os efeitos do uso dos solos na atenuação da energia cinética das chuvas em áreas de grandes dimensões, como o município de Jataí.

Assim sendo, objetivou-se, com o presente estudo, estimar a energia cinética das chuvas e simular, por meio do uso de modelos, o efeito da cobertura vegetal como fator de redução do impacto de precipitações 
pluviométricas na bacia hidrográfica do Ribeirão Paraíso, em duas épocas de cultivo.

\section{MATERIAIS E MÉTODOS}

\subsection{LOCALIZAÇÃO E CARACTERIZAÇÃO DA ÁREA DE ESTUDO}

O presente estudo foi realizado para a bacia hidrográfica do Ribeirão Paraíso, no município de Jataí, microrregião do Sudoeste de Goiás (Figura 1), localizada entre as latitudes $17^{\circ} 15^{\prime} \mathrm{S}$ e $17^{\circ} 51^{\prime} \mathrm{S}$ e as longitudes de $51^{\circ} 39^{\prime} \mathrm{W}$ e $51^{\circ} 57^{\prime} \mathrm{W}$; e altitude variando de 640 a 1030m. De acordo com a classificação climática de Köppen, a região do Cerrado é classificada como tropical de savana (Aw), com regime chuvoso entre outubro e abril, quando ocorrem $90 \%$ das precipitações (ASSUNÇÃO et al., 2008). Essa bacia hidrográfica foi escolhida por representar um sistema completo em termos de captação hidrológica, utilizada com agricultura intensiva, dentro do município de Jataí. Ademais, a referida bacia também possui divisor de águas bem definido.
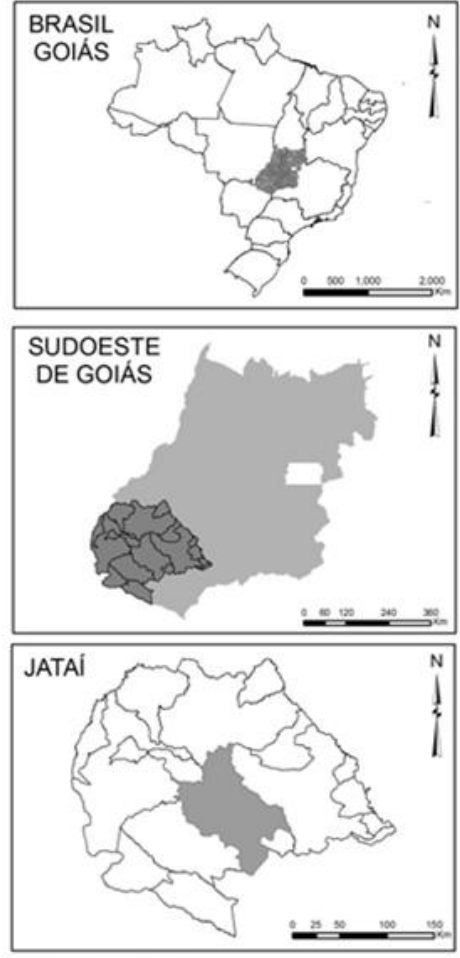

Fonte: SIEG, 2012

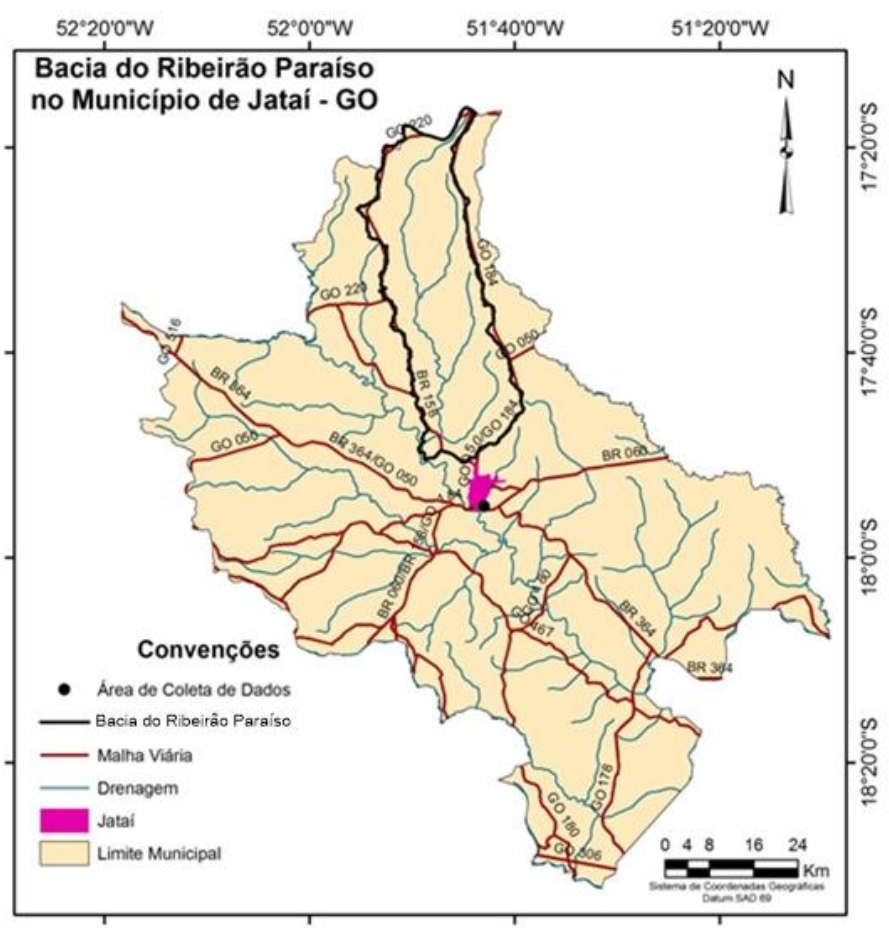

Organizaçao: LIMA, H. F., 2012

Figura 1- Localização geográfica da área de estudo.

A bacia hidrográfica do Ribeirão Paraíso é caracterizada por relevos planos a ondulados (GUERRA, PEREIRA, et al., 1989), sendo composta por densa rede de drenagem, tendo o Ribeirão Paraíso como canal principal e os córregos das Pedras, da Onça e Bom Sucesso, como canais secundários ou subbacias hidrográficas. Dentre os tipos de solos predominam os Latossolos, seguidos por Cambissolos, Argissolos e Gleissolos, com menores frequências de Neossolos Quartzarênicos e Nitossolos (RADAMBRASIL, 1983; EMBRAPA, 2006). A vegetação nativa desta bacia é remanescente de distintas fitofisionomias do Cerrado (RIZZINI, 1979; EITEN, 1993) configuradas por Cerradão, Cerrado 
Sentido Restrito, Campo Sujo, Campo Limpo e Mata de Galeria. A vegetação original foi substituída, em grande parte, por atividades agropecuárias (FERREIRA et al., 2007).

\subsection{COLETA E TRATAMENTO DOS DADOS}

Para o estudo, conduzido na Universidade Federal de Goiás, Campus Jataí, inicialmente foi realizado o monitoramento diário das variáveis ambientais na estação meteorológica da instituição $\left(17^{\circ} 55^{\prime} \mathrm{S}, 51^{\circ} 43^{\prime} \mathrm{W}, 670 \mathrm{~m}\right.$ ), pelo período de um ano, com observações iniciadas em fevereiro de 2012. Foram executados, ainda, o cálculo das variáveis topográficas, a classificação do uso do solo, a simulação espacial e temporal da energia cinética das chuvas e a classificação do efeito atenuante da cobertura dos solos.

As variáveis ambientais utilizadas referem-se às informações meteorológicas diárias das componentes direcionais e verticais das chuvas $(\mathrm{mm})$, bem como da velocidade média do vento $\left(\mathrm{m} \cdot \mathrm{s}^{-1}\right)$. Para obtenção das componentes direcionais das chuvas foi utilizada uma bateria de pluviômetros vetoriais simples (Figura 2), orientados nas direções Norte (PN), Sul (PS), Leste $(P E)$ e Oeste (PW), com áreas coletoras inclinadas em $45^{\circ}$. A componente vertical (P) das chuvas foi medida com um pluviômetro normal. Esses instrumentos foram confeccionados em PVC, com área coletora de $163 \mathrm{~cm}^{2}$ (ASSUNÇÃO, SCOPEL, et al., 2004). Os instrumentos foram instalados a 1,5 m de altura.

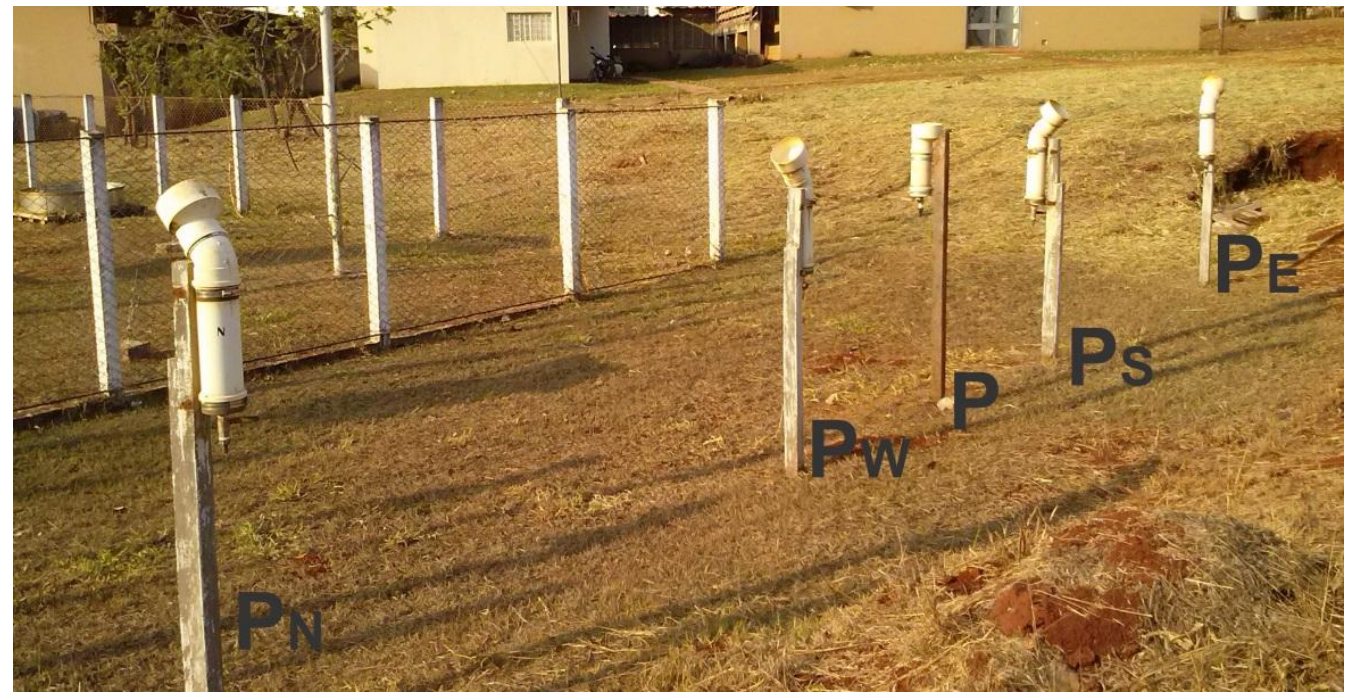

Figura 2 - Bateria de pluviômetros vertical $(P)$, e pluviômetros direcionais, orientados nas direções Norte (PN), Sul (PS), Leste (PE) e Oeste (PW), com áreas coletoras inclinadas em $45^{\circ}$, na estação meteorológica da Universidade Federal de Goiás, Campus Jataí. (foto: LIMA, 2012).

Os volumes de chuvas coletados nos pluviômetros vertical e direcionais foram medidos manualmente, utilizando uma proveta com capacidade para 250 $\mathrm{cm}^{3}$, e, posteriormente, convertidos em milímetros $(\mathrm{mm})$, de acordo com a Equação 1. 


$$
H=\frac{V}{163} \cdot 10
$$

Em que: $H$, em $m m$, é a lâmina de chuva atribuída às componentes direcionais (PN, PS, PE, PW) e vertical $(P)$; $V$ é o volume, em $\mathrm{cm}^{3}$, coletado diretamente nos pluviômetros; 163 é a constante referente à área de captação do instrumento em $\mathrm{cm}^{2}$; e 10 , a constante de conversão.

Para fins de aferição e calibração do pluviômetro de $163 \mathrm{~cm}^{2}$, as medidas da componente vertical das chuvas ( $P$ ) foram correlacionadas com aquelas registradas pelo pluviômetro padrão INMET para o ano de 2013.

A direção das chuvas $\Omega\left(^{\circ}\right)$ e a inclinação $i\left({ }^{\circ}\right)$, em relação ao zênite, foram estimadas de acordo com ASSUNÇÃO et al. (2004), de acordo com a Equação 2 e a Equação 3:

$$
\Omega=\tan ^{-1}\left(\frac{P_{Y}-P \cdot \cos \beta}{P_{X}-P \cdot \cos \beta}\right)
$$

e

$$
i=\tan ^{-1}\left(\frac{P_{X}-P \cdot \cos \beta}{P \cdot \sin \beta \cdot \cos \Omega}\right)
$$

Em que: $\beta$ é a inclinação do pluviômetro vetorial $\left(45^{\circ}\right)$; $P$ é a componente vertical da chuva; $P_{Y}=\max \left(P_{E} ; P_{W}\right)$ é o máximo valor entre as precipitações medidas nos sentidos Leste e Oeste; e $P_{X}=\max \left(P_{N} ; P_{S}\right)$ é o máximo valor entre as precipitações medidas nos sentidos Norte e Sul.

A componente da velocidade do vento foi obtida, junto à Plataforma de Coleta de Dados (PCD) do INMET para o ano de 2013, e foi medida a $10 \mathrm{~m}$ de altura. Para fins de compatibilidade com a altura dos pluviômetros, a velocidade média do vento $\left(u_{10}\right)$ foi estimada para $2 \mathrm{~m}$ de altura $\left(u_{2}\right)$, usando a Equação 4, recomendada pelo boletim no56 da FAO (ALLEN, PEREIRA, et al., 1998):

$$
u_{2}=u_{10} \cdot 4,87 / \ln (67,8 \cdot 10-5,42)
$$

A velocidade terminal das gotas de chuva $\left(V_{r}\right)$, em $\mathrm{m} \cdot \mathrm{s}^{-1}$, foi estimada de acordo com a Equação 5, conforme Guo et al. (2001):

$$
V_{r}=\frac{u_{2}}{\sin i}
$$

Os dados meteorológicos de precipitações direcionais e vertical, associados aos de velocidade do vento foram processados dia-a-dia, e integrados mensalmente a fim de abranger os períodos agrícolas, de safrinha (fevereiro a maio/2012) e de safra (outubro/2012 a janeiro/2013).

Originalmente os dados de elevação do terreno estavam em coordenadas geodésicas (latitude, longitude e altitude), posteriormente esses foram convertidos para coordenadas UTM $(E, N, Z)$ e interpolados espacialmente em grade regular de $30 \mathrm{~m}$, pela técnica Kriging, utilizando o software Surfer versão 2011 (SURFER 11, 2013).

A declividade $(\alpha)$ e a orientação das vertentes ( $\omega)$, em graus, foram derivadas do modelo de elevação do terreno, usando o software Surfer. Esse 
calcula a declividade (Terrain Slope), de acordo com a Equação 6, baseada na fórmula de Moore et al. (1993):

$$
\alpha \approx \frac{360}{2 \pi} \cdot \tan ^{-1} \cdot\left[\sqrt{\left(\frac{Z_{E-} Z_{W}}{2 \cdot \Delta X}\right)^{2}+\left(\frac{Z_{N-} Z_{S}}{2 \cdot \Delta Y}\right)^{2}}\right]
$$

Enquanto que a orientação azimutal das vertentes (Terrain Aspect) foi estimada pontualmente, de acordo com a Equação 7, de Moore et al. (1993):

$$
\omega \approx 270-\frac{360}{2 \pi} \cdot \tan ^{-1}\left[\frac{Z_{N}-Z_{S}}{2 \cdot \Delta Y} / \frac{Z_{E}-Z_{W}}{2 \cdot \Delta X}\right]
$$

Em que: $Z$ é um ponto central de elevação no terreno, o qual é tomado como referência para a elevação dos vizinhos mais próximos ao norte $\left(Z_{N}\right)$, ao sul $\left(Z_{S}\right)$, ao leste $\left(Z_{E}\right)$, e a oeste $\left(Z_{W}\right) ; \Delta x$ é a variação das coordenadas no eixo $X ; \Delta y$ é a variação das coordenadas no eixo $\mathrm{Y}$.

As orientações das vertentes foram classificadas de acordo com os intervalos azimutais apresentados na Tabela 1. Nesta etapa foram gerados, para a bacia hidrográfica do Ribeirão Paraíso, os planos de informações da declividade e orientação das vertentes, necessários para o cálculo da energia cinética de acordo com a intensidade, direção e inclinação das chuvas.

Tabela 1 - Classes de orientações das vertentes $\omega\left(^{\circ}\right.$ - graus), para a bacia hidrográfica do Ribeirão Paraíso, município de Jataí, microrregião do Sudoeste de Goiás.

\begin{tabular}{lll}
\hline Intervalo de $\boldsymbol{\omega}\left(^{\circ}\right)$ & Centro de $\boldsymbol{\omega}\left(^{\circ}\right)$ & Orientação \\
\hline $337,5-22,5$ & 0 & Norte \\
$22,5-67,5$ & 45 & Nordeste \\
$67,5-112,5$ & 90 & Leste \\
$112,5-157,5$ & 135 & Sudeste \\
$157,5-202,5$ & 180 & Sul \\
$202,5-247,5$ & 225 & Sudoeste \\
$247,5-292,5$ & 270 & Oeste \\
$292,5-337,5$ & 315 & Noroeste \\
\hline
\end{tabular}

Com base nos planos de informações das variáveis topográficas $(\alpha, \omega)$, utilizou-se a Equação 8 no aplicativo Surfer para o cálculo da precipitação normal $\left(P_{\alpha}\right)$, interceptada pelo terreno (ASSUNÇÃO, MARTINS, et al., 2011):

$$
P_{\alpha}(i, \Omega)=\frac{P}{\cos i} \cdot[\cos i \cdot \cos \alpha+\sin i \cdot \sin \alpha \cdot \cos (\Omega-\omega)]
$$

Em que: $P$ é a componente vertical da chuva $(\mathrm{mm}) ; \Omega\left({ }^{\circ}\right.$ - graus) é a direção das chuvas; $i$ ( ${ }^{\circ}$ - graus) é a inclinação da chuva.

Desprezando-se a presença de cobertura vegetal na área da bacia hidrográfica, bem como as forças contrárias envolvidas no sistema, o plano de informação atribuído à variável $P_{\alpha}$ foi utilizado para o cálculo da energia cinética $(E C)$, em MJ.ha-1 ${ }^{-1}$ diária das chuvas (Equação 9): 


$$
E C=0,01 \cdot \frac{P_{\alpha} \cdot V_{r}^{2}}{2}
$$

Os planos de informações diários de EC foram utilizados para efetuar as simulações e classificação do efeito atenuante da cobertura vegetal dos solos durante o período de safrinha e de safra na bacia hidrográfica do Ribeirão Paraíso, no município de Jataí (GO).

As classes de uso do solo da bacia (Erro! Fonte de referência não encontrada.) foram geradas no laboratório de geoinformação da UFG/Campus Jataí, às quais foram atribuídos distintos coeficientes de atenuação da chuva $\left(k_{a}\right)$ de acordo com o período agrícola (safrinha e safra).

Tabela 2- Classes de uso do solo, características e coeficientes de atenuação da chuva (ka)

\begin{tabular}{llll}
\hline Classes & Características & $k_{a}$ & Fonte \\
\hline Agricultura & $\begin{array}{l}\text { Culturas de safra (soja) e de } \\
\text { safrinha (milho) }\end{array}$ & $\begin{array}{l}\text { Equações 10 e } \\
11\end{array}$ & $\begin{array}{l}\text { (SILVA JÚNIOR, } \\
\text { ASSUNÇÃO, et } \\
\text { al., 2013) }\end{array}$ \\
$\begin{array}{l}\text { Campo } \\
\text { aberto }\end{array}$ & $\begin{array}{l}\text { Solo decoberto, areais, e } \\
\text { água }\end{array}$ & 0 & \\
Pastagem & $\begin{array}{l}\text { Pastagens cultivadas, } \\
\text { naturais e campo sujo }\end{array}$ & Equação 12 & $\begin{array}{l}\text { (SILVA JÚNIOR, } \\
\text { ASSUNÇÃO, et } \\
\text { al., 2013) } \\
\text { (CARVALHO, }\end{array}$ \\
& $\begin{array}{l}\text { Reservas de preservação } \\
\text { permanente e legais (matas } \\
\text { Reservas }\end{array}$ & $0,49-0,19$ & 2011) \\
\hline
\end{tabular}

$$
k_{a}=-0,00075 \cdot D A S^{2}+0,0778 \cdot D A S-0,582 ; \quad 8<D A S<96
$$

Da mesma forma, para o milho de safrinha, foi ajustada a Equação 11, a partir de dados de Silva Júnior (2013):

$$
k_{a}=-0,000212 \cdot D A S^{2}+0,0362 \cdot D A S-0,0735 ; \quad 3<D A S<160
$$

A Equação 12, ajustada aos dados de Silva Júnior (2013), descreve o desenvolvimento das pastagens:

$$
k_{a}=-0,000382 \cdot D A S^{2}+0,06681 \cdot D A S-0,69495 ; \quad 12<D A S<163
$$

Com estes coeficientes foi calculado o fator atenuante $\left(f_{a}\right)$ da chuva, de acordo coma Equação 13:

$$
f_{a}=e^{-k_{a}}
$$

Com a Equação 13 foi possível o recálculo da energia de impacto direto $\left(E C_{\text {uso }}\right)$, resultante da interação com a cobertura vegetal, que consequentemente reduz a energia liberada no impacto (Equação 14): 


$$
E C_{\text {uso }}=f_{a} \cdot E C
$$

O efeito atenuante da cobertura vegetal do solo Ef (\%), sobre a energia cinética das chuvas, foi definido de acordo com a Equação 15:

$$
E f=\frac{E C-E C_{\text {uso }}}{E C} \cdot 100
$$

Em que: $E C_{\text {uso }}$ é a energia cinética, considerando a cobertura do solo de acordo com o seu uso; EC é a energia cinética das chuvas, desprezando a cobertura. Para fins analíticos, o efeito atenuante da cobertura vegetal do solo Ef(\%) para a energia cinética das chuvas foi classificado de acordo com a Erro! Fonte de referência não encontrada.

Tabela 3- Classificação do efeito atenuante da cobertura vegetal

\begin{tabular}{cc}
\hline Intervalo de $E f(\%)$ & Classes \\
\hline 0 a 5 & NULO \\
5 a 15 & BAIXO \\
15 a 35 & MÉDIO \\
35 a 75 & ALTO \\
75 a 100 & MUITO ALTO \\
\hline
\end{tabular}

\section{RESULTADOS E DISCUSSÃO}

\subsection{CARACTERIZAÇÃO DAS PRECIPITAÇÕES}

Foi obtida correlação linear positiva entre a precipitação medida no pluviômetro padrão INMET e aquela obtida no pluviômetro de $163 \mathrm{~cm}^{2}$, observados durante o período de estudo (Figura 3). A análise de regressão explica $97 \%$ da linearidade entre o conjunto de dados medidos por ambos os instrumentos, de acordo com o coeficiente de determinação. Em termos médios, o coeficiente linear ou de calibração é de 1,01 , indicando um erro não significativo de $1 \%$, nas medidas do pluviômetro de $163 \mathrm{~cm}^{2}$. O que não impede o uso dos dados obtidos com os pluviômetros confeccionados em PVC no presente estudo. A dispersão dos dados possivelmente está associada à velocidade do vento, a qual se torna mais evidente em instrumentos com menor área de captação (GUO, URBONAS e STEWART, 2001). 


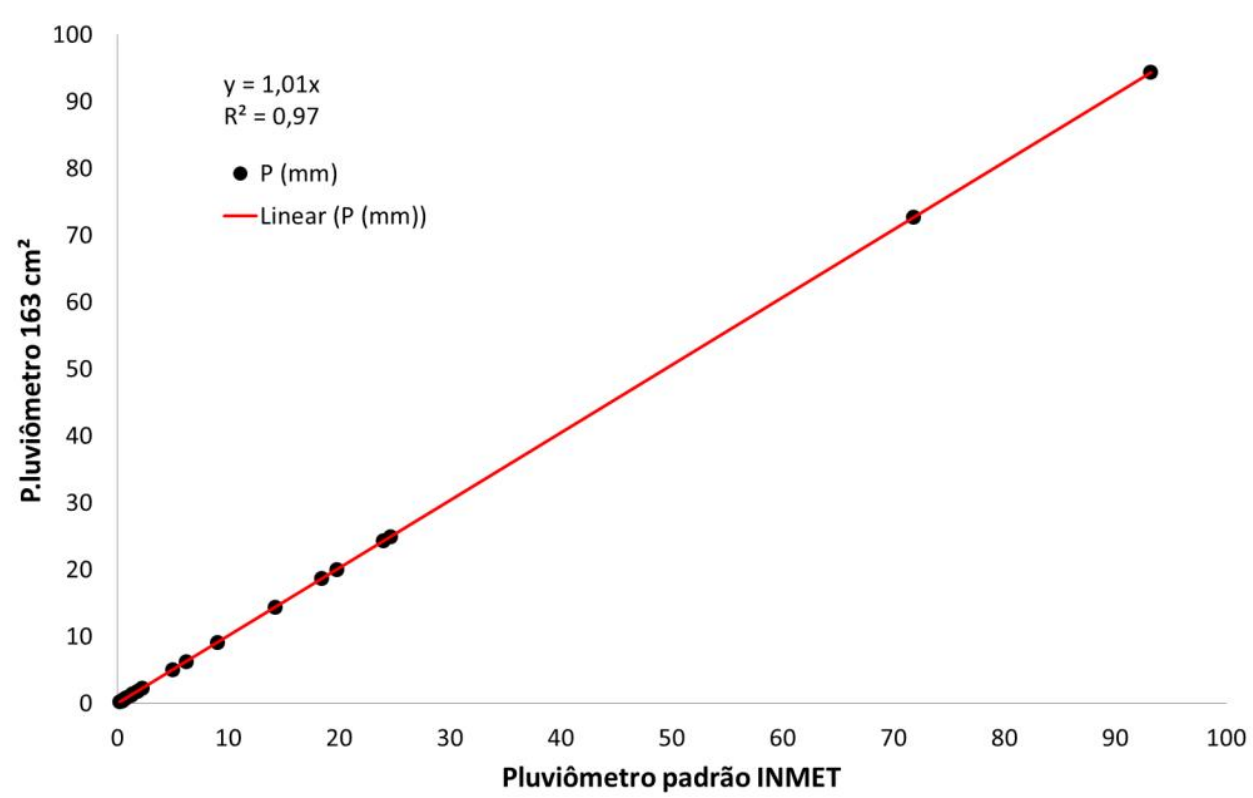

Figura 3 - Correlação entre dados do pluviômetro vertical confeccionado em PVC com $163 \mathrm{~cm}^{2}$ de área de captação e dados do INMET.

A Tabela 4 sintetiza os totais mensais das componentes verticais das precipitações, bem como as médias mensais da direção, inclinação das chuvas e da velocidade do vento, durante os meses de estudo. As precipitações mensais variaram entre 47,4 mm (maio/2012) e 252,6 mm (janeiro/2013). Nota-se que a direção predominante das chuvas é sudeste (4 meses), seguida por chuvas vindas de sul (2 meses), no mês de maio, as chuvas vieram da direção leste, e no mês de outubro vieram de sudoeste. As maiores inclinações das chuvas ocorreram nos meses de maio, outubro e dezembro de 2012, associadas às menores precipitações e às maiores velocidades dos ventos. Assunção (2011), trabalhando com dados agrupados para a primavera, verão, outono e inverno, também observou que a maior parte das chuvas veio do Sudoeste, com inclinação média da chuva de $21^{\circ}$, nas dependências do campus da UFG em Jataí.

Tabela 4 - Precipitações mensais da componente vertical da chuva (P), média da direção das chuvas $(\overline{\boldsymbol{\Omega}})$, quadrantes, média da inclinação das chuvas $(\overline{\boldsymbol{\imath}})$, velocidade média do vento a 2 metros de altura $\left(\overline{\boldsymbol{u}_{2}}\right)$ e velocidade média terminal das chuvas ( $\mathrm{Vr}$ )

\begin{tabular}{cccccccc}
\hline ANO & MÊS & $\mathrm{P}(\mathrm{mm})$ & $\bar{\Omega}\left({ }^{\circ}\right)$ & Quadrante & $\bar{\imath}\left({ }^{\circ}\right)$ & $\overline{u_{2}}\left(\mathrm{~m} . \mathrm{s}^{-1}\right)$ & $\mathrm{Vr}\left(\mathrm{m} \cdot \mathrm{s}^{-1}\right)$ \\
\hline & FEV & 244,3 & 146,7 & SE & 9,3 & 1,4 & 8,2 \\
& MAR & 223,5 & 137,4 & SE & 7,9 & 1,6 & 9,4 \\
& ABR & 154,6 & 140,7 & SE & 6,4 & 1,7 & 12,5 \\
& MAI & 47,4 & 96,5 & E & 10,3 & 1,4 & 10,1 \\
& OUT & 115,3 & 207,3 & SW & 11,6 & 2,5 & 15,8 \\
& NOV & 225,7 & 190,4 & S & 6,1 & 1,6 & 13 \\
& DEZ & 126,6 & 183,4 & S & 12 & 2,0 & 7,8 \\
& JAN & 252,6 & 140,4 & SE & 6,2 & 1,5 & 13,7 \\
\hline
\end{tabular}


As velocidades médias terminais das chuvas variaram de 7,8 m.s- 1 (dezembro/2012) a 15,8 m.s-1 (outubro/2012), as quais são diretamente proporcionais à velocidade do vento e inversamente proporcionais ao seno da inclinação da chuva. Significando que a energia cinética também variou nesse período, causando maiores impactos no solo.

\subsection{DISTRIBUIÇÃO ESPACIAL DA DECLIVIDADE E ORIENTAÇÃO DAS VERTENTES}

A área total da bacia hidrográfica do Ribeirão Paraíso, em Jataí (GO), é de $90.329,8$ ha, topograficamente distribuída de acordo com as classes de declividade, apresentadas na Figura 4A. Na bacia hidrográfica do Ribeirão Paraíso, predominam relevos dos tipos: plano $(48,3 \%$ da área) e suave ondulado $(38,8 \%)$, principalmente nas chapadas e fundos de vale. Observa-se também que, em apenas $12,9 \%$ da área da bacia, ocorrem classes de relevo variando de moderado ( 8 a $13 \%$ de inclinação) a fortemente ondulado (inclinação de 20 a 45\%), principalmente nas transições das chapadas planas com as nascentes dos cursos d'água.
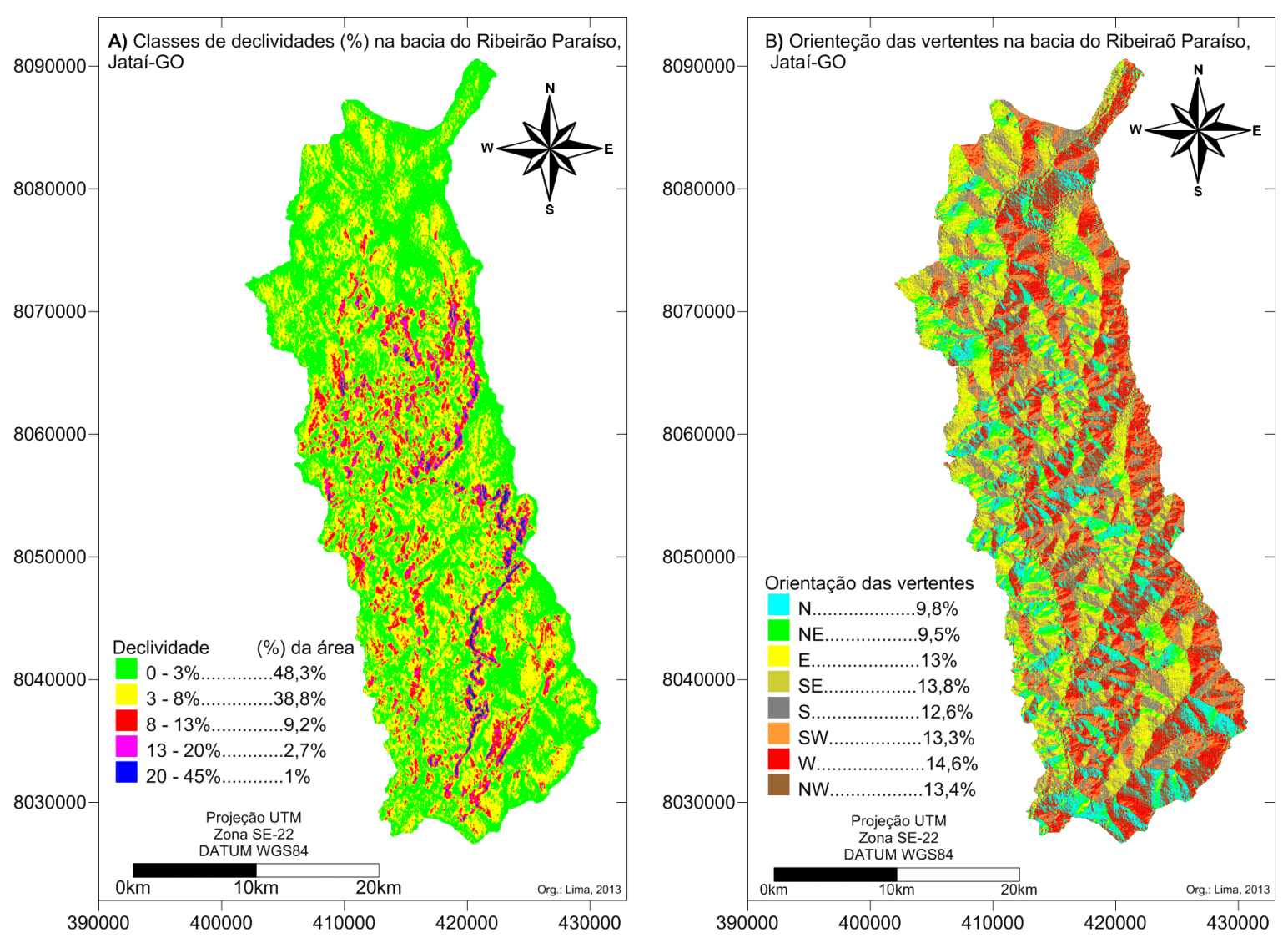

Figura 4 - Classes de declividade (A); orientação das vertentes (B) da bacia hidrográfica do Ribeirão Paraíso, Município de Jataí, Goiás. 
Ainda que cultivadas esporadicamente e mesmo ocorrendo em baixas frequências, as classes de relevo com maior inclinação merecem atenção especial quanto ao manejo do solo. Conforme Ferreira et al. (1985), declives de aproximadamente $20 \%$ mostraram menos erosão do que encostas com $10 \%$ a $11 \%$ de declividade, para a mesma quantidade de escoamento. Tais fatos foram atribuídos à orientação dos campos com relação à direção predominante dos ventos e das chuvas. Dentre as consequências da perda de solo superficial por ação da erosão hídrica ou eólica estão a diminuição da fertilidade e também a redução da capacidade de escoamento dos rios por causa da sedimentação (LIMA, 1989).

A Figura 4B apresenta a distribuição da orientação das vertentes na bacia hidrográfica do Ribeirão Paraíso. Com exceção das vertentes norte $(9,8 \%)$ e nordeste $(9,5 \%)$, pode-se notar que as demais vertentes se distribuem uniformemente, com frequência variando de $12,6 \%$ (S) a $14,6 \%$ (W). As menores frequências das vertentes norte e nordeste são explicadas pela rede de drenagem do tipo dendrítica (CHRISTOFOLETTI, 1980) orientada longitudinalmente, com águas superficiais fluindo do norte, nordeste e noroeste da bacia, em direção ao Rio Claro, ao sul. Assim, conclui-se que $87,1 \%$ da superfície da bacia hidrográfica do Ribeirão Paraíso possui declividade abaixo de $8 \%$, distribuída sobre uma rampa norte-sul de aproximadamente $62 \mathrm{~km}$, entre a nascente e a foz.

\subsection{DISTRIBUIÇÃO DAS CLASSES DE USO DO SOLO NA BACIA DO RIBEIRÃO PARAÍSO}

A distribuição de uso do solo em função do relevo na bacia hidrográfica do Ribeirão Paraíso é apresentada na Tabela 5 . Nota-se que nesta bacia $100 \%$ das áreas exploradas com agricultura estão localizadas em solos de relevo plano $(63,5 \%)$ e suave ondulado $(36,5 \%)$ (Tabela 5$)$. A razão disso está no fato de que áreas com baixa declividade são aquelas mais indicadas para a exploração com agricultura mecanizada.

Tabela 5 - Distribuição de uso do solo em função do relevo da bacia hidrográfica do Ribeirão Paraíso, Município de Jataí, Goiás.

\begin{tabular}{lcccc}
\hline \multirow{2}{*}{ TIPO DE RELEVO } & \multicolumn{3}{c}{ USO DO SOLO (\%) } \\
\cline { 2 - 5 } & AGRICULTURA & PASTAGEM & RESERVAS & $\begin{array}{c}\text { CAMPO } \\
\text { ABERTO }\end{array}$ \\
\hline Plano & 63,5 & 28,9 & 43,3 & 0 \\
Suave ondulado & 36,5 & 56,2 & 36,6 & 0 \\
Moderadamente ondulado & 0 & 10,5 & 14,2 & 72,5 \\
Ondulado & 0 & 3,2 & 4,2 & 20,9 \\
Forte ondulado & 0 & 1,2 & 1,7 & 6,6 \\
\hline
\end{tabular}

De acordo com a Tabela 5 e a Figura 5, as pastagens são observadas em todas as classes de relevo. Ocorre predomínio dessa classe de uso do solo em relevo suave ondulado $(56,2 \%)$, seguida por relevo plano $(28,9 \%)$, moderadamente ondulado $(10,5 \%)$, ondulado $(3,2 \%)$ e fortemente ondulado $(1,2 \%)$. A distribuição atual das pastagens provavelmente esteja ligada à substituição destas pela agricultura, principalmente em áreas de relevo plano. As pastagens existentes nas classes de relevo ondulado e fortemente ondulado 
possivelmente são remanescentes de pastagens nativas, uma vez que estas classes de relevo são recomendadas para uso como reserva legal e áreas de preservação permanente.

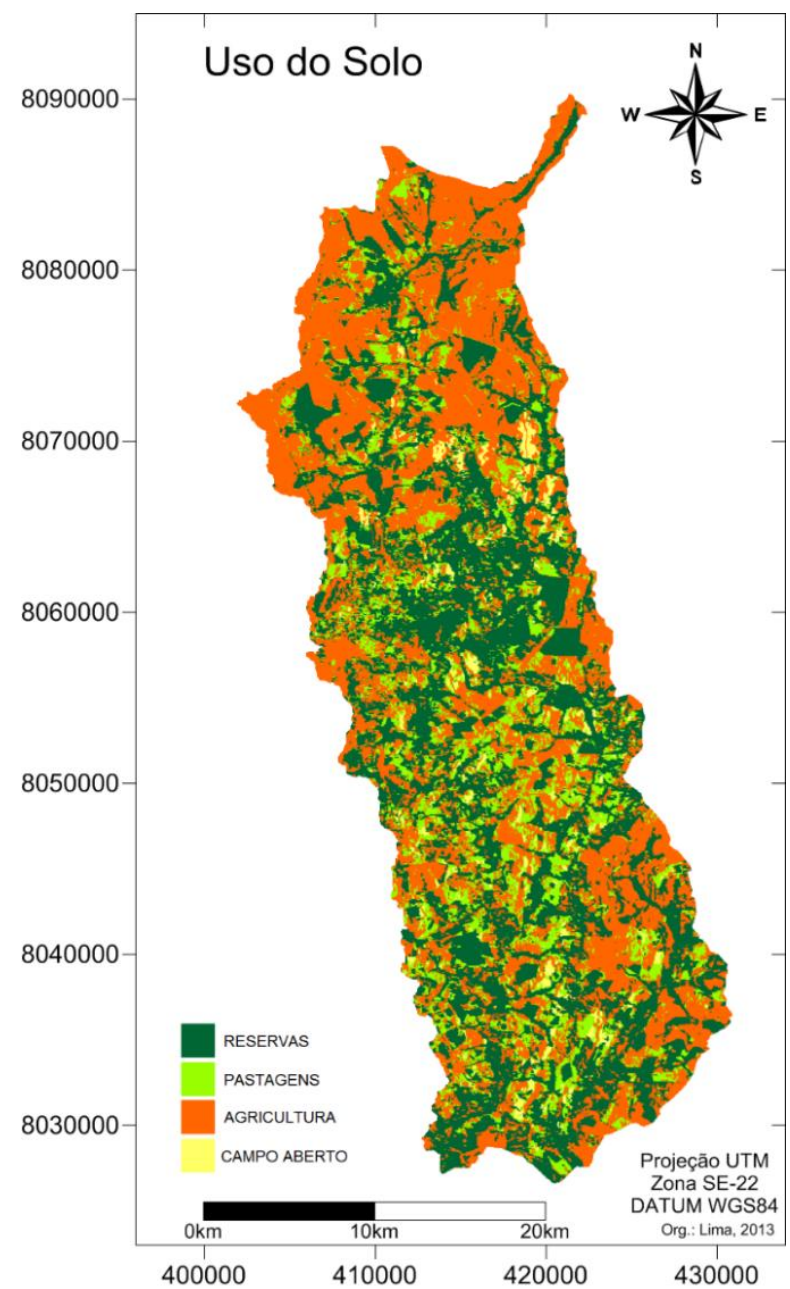

Figura 5 - Distribuição do uso do solo na bacia do Ribeirão Paraíso, Município de Jataí, Goiás.

As reservas estão presentes em todas as classes de relevo (Tabela 5 e a Figura 5). No relevo plano estas totalizam 43,3\%, correspondendo às áreas planas das cabeceiras da rede de drenagem, bem como áreas planas com afloramento rochoso ou cascalhentas, impróprias para agricultura. As reservas, representadas pelas matas ciliares, encontram-se distribuídas sobre o relevo suave ondulado, com $36,6 \%$ de frequência. As reservas, como matas de encostas, são encontradas nas bordas das chapadas, sobre relevo moderado e/ou fortemente ondulado, totalizando $20,1 \%$.

Observando a Figura 5, pode-se notar que os campos abertos podem ser encontrados em áreas de topografia acidentada, solos arenosos expostos, corpos d'água e, ainda, em solos expostos como afloramento de rochas ou cascalhos. Pela Tabela 5 , as suas frequências correspondem ao relevo 
moderadamente ondulado, 72,5\%; ondulado, 20,9\%; e fortemente ondulado, $6,6 \%$.

\subsection{MÉdIAS MENSAIS SIMULAdAS PARA A ENERGIA CINÉTICA DAS CHUVAS}

As médias mensais da energia cinética das chuvas são apresentadas na Tabela 6. Essas foram simuladas considerando os efeitos atenuantes da cobertura e uso do solo, para os períodos de safrinha e safra. A média espacial da energia cinética das chuvas simuladas (EC) apresentou variação de $671,49 \mathrm{MJ}$.ha-1, entre maio/2012 e abril/2012. Esta variação sugere que os maiores impactos estão associados à intensidade, duração, inclinação e direção das chuvas e ainda às variações topográficas da bacia (declividade e orientação das vertentes).

Tabela 6 - Média da energia cinética simulada $(\overline{\mathbf{E C}})$; média da energia cinética simulada sobre a cobertura do solo de acordo com o uso $\left(\overline{\mathbf{E C}}_{\text {uso }}\right)$; efeito da cobertura do solo na redução da energia cinética (Ef). $M J \cdot \mathrm{ha}^{-1} \cdot \mathrm{mês}^{-1}$ - megajoule por hectare mês.

\begin{tabular}{|c|c|c|c|c|c|c|}
\hline \multirow{2}{*}{ ANO } & & \multirow{2}{*}{ MÊS } & $\overline{E C}$ & $\overline{E C}_{\text {uso }}$ & $\overline{E C}-\overline{E C}_{\text {uso }}$ & \multirow{2}{*}{$\begin{array}{r}E f \\
(\%)\end{array}$} \\
\hline & & & \multicolumn{3}{|c|}{ MJ.ha' $a^{-1} \cdot \mathrm{mês}^{-1}$} & \\
\hline \multirow{7}{*}{2012} & \multirow{4}{*}{ Safrinha } & Fev. & 141,4 & 96,3 & 45,1 & 31,9 \\
\hline & & Mar. & 380,1 & 321,1 & 59,0 & 15,5 \\
\hline & & Abr. & 688,3 & 590,7 & 97,6 & 14,2 \\
\hline & & Maio & 16,9 & 14,4 & 2,5 & 14,8 \\
\hline & \multirow{4}{*}{ Safra } & Out. & 227,5 & 101,2 & 126,3 & 55,5 \\
\hline & & Nov. & 508,6 & 183,1 & 325,5 & 64,0 \\
\hline & & Dez. & 92,9 & 29,5 & 63,4 & 68,2 \\
\hline 2013 & & Jan. & 561,2 & 214,1 & 347,1 & 61,8 \\
\hline
\end{tabular}

Verifica-se, ainda na Tabela 6 , que a energia cinética das chuvas simuladas sob as condições de uso do solo (ECuso) apresenta a mesma tendência da simulação anterior. Porém, é observada menor amplitude de variação, resultando em maior efeito dispersivo dos dados principalmente quando ocorreram os maiores valores de EC. As diferenças entre a energia cinética simulada de chuvas com e sem cobertura vegetal (EC-ECuso) são refletidas pelo efeito atenuante da cobertura do solo (Ef), reduzindo o impacto das chuvas na superfície da bacia.

Para o período entre fevereiro e maio/2012 (safrinha), a cobertura do solo teve efeito redutor na energia cinética das chuvas, variando de $14,2 \%$ (abril/2012) a 31,9\% (fevereiro/2012). Para o período de outubro/2012 a janeiro/2013 (safra), o efeito atenuante sobre a energia cinética da chuva variou de 55,5\% (outubro/2012) a 68,2\% (dezembro/2012). Os maiores efeitos atenuantes sobre a energia cinética das chuvas simuladas durante o período da safra, provavelmente estão associados aos coeficientes de atenuação da chuva (ka), os quais são diretamente proporcionais à cobertura do solo, maior no 
período chuvoso. A cultura da soja, semeada em espaçamento mais adensado que a cultura do milho proporcionou maior proteção ao solo.

\subsection{EFEITO ATENUANTE DA COBERTURA DO SOLO SOBRE A ENERGIA CINÉTICA SIMULADA - SAFRINHA 2012}

O efeito atenuante da cobertura do solo sobre a energia cinética das chuvas durante o mês de fevereiro de 2012 é apresentado na Figura 6A. A precipitação acumulada para o mês foi de $244,3 \mathrm{~mm}$, com inclinação média (i) de $9,3^{\circ}$; predominantemente vinda da direção $\operatorname{SE}\left(\Omega=146,7^{\circ}\right)$, resultando em velocidade terminal da chuva $(\mathrm{Vr})$ de $8,2 \mathrm{~m} . \mathrm{s}^{-1}$. Com esses parâmetros, a simulação do efeito atenuante da cobertura do solo sobre a energia cinética das chuvas discriminou as classes MÉDIA (57\%) e ALTA (43\%). Nota-se na Figura $6 \mathrm{~A}$ que a classe mais frequente do efeito atenuante ocorreu sobre as vertentes e fundos de vales, dominados por reservas e pastagens, enquanto que a classe ALTA do efeito atenuante ocorreu sobre as chapadas dominadas pela cultura do milho, dentro da área da bacia hidrográfica do Ribeirão Paraíso.
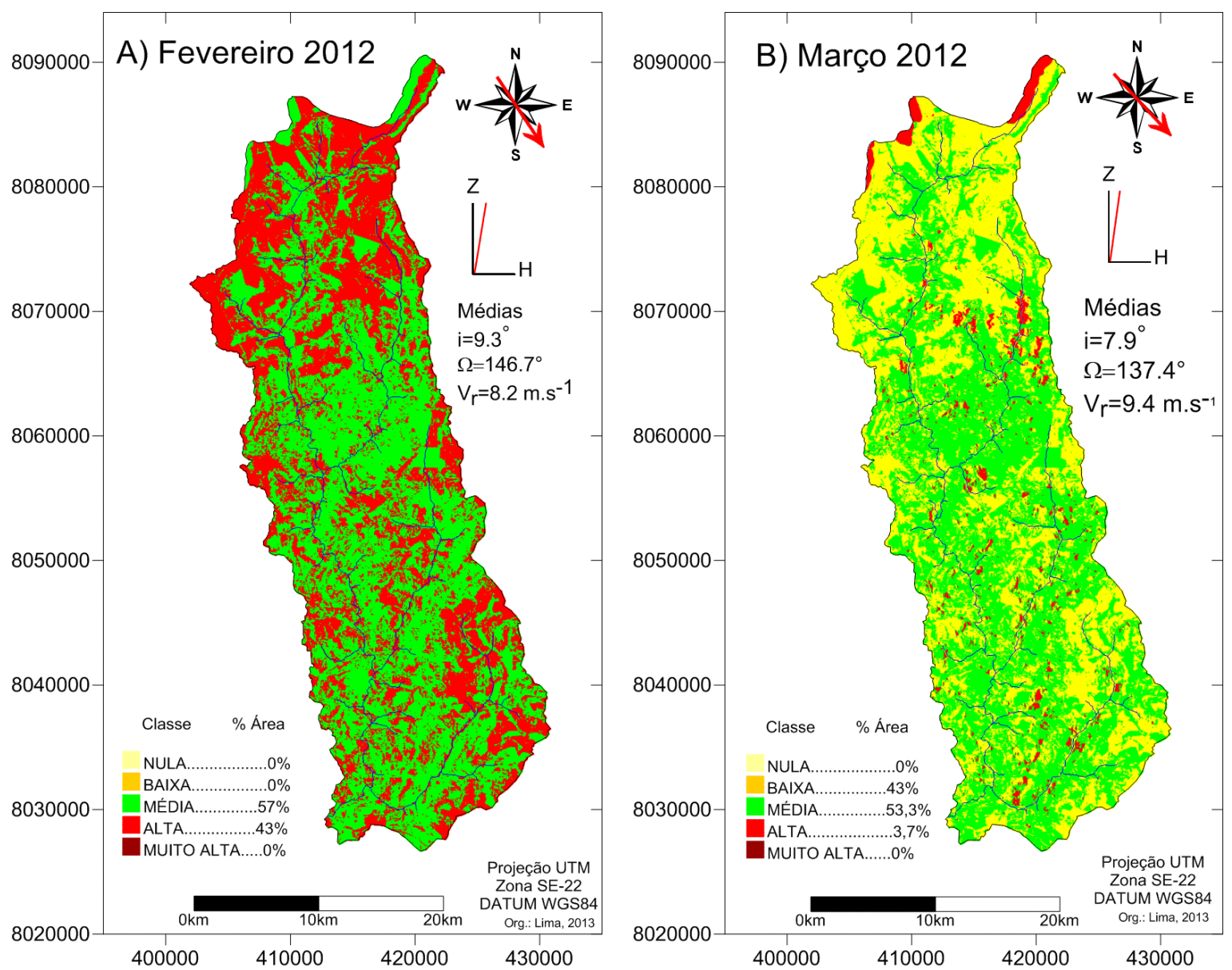

Figura 6 - Classes do efeito atenuante (Ef) da cobertura do solo sobre a energia cinética das chuvas simulada para a bacia hidrográfica do Ribeirão Paraíso (Município de Jataí, Goiás): A) mês de fevereiro/2012; B) mês de março/2012. Em que: i é a inclinação média; $\square \square$ é a direção; e Vr é a velocidade terminal da chuva. 
A Figura 6B mostra o efeito atenuante da cobertura do solo sobre a energia cinética da chuva para o mês de março de 2012. A precipitação acumulada foi de $223,5 \mathrm{~mm}$, vinda de $\operatorname{SE}\left(\Omega=137,4^{\circ}\right)$, com i de $7,9^{\circ}$, resultando em $\mathrm{Vr}$ de $9,4 \mathrm{~m} \cdot \mathrm{s}^{-1}$. Com esses parâmetros, a simulação do efeito atenuante da cobertura do solo sobre a energia cinética das chuvas discriminou as classes BAIXA (43\%), MÉDIA (53,3\%) e ALTA (3,7\%). Nota-se na Figura 6B que a classe mais frequente do efeito atenuante ocorreu nas áreas consideradas de reserva, tanto em zonas de chapadas como em áreas de matas ciliares. As áreas classificadas como de BAIXA atenuação, abrangiam aquelas onde as culturas ainda estavam em desenvolvimento. Em estágios iniciais de desenvolvimento, a cobertura vegetal exercida pelas culturas é bastante reduzida, havendo mais solo exposto à ação erosiva das precipitações. E, finalmente, a classe de atenuação ALTA ocorreu em áreas diversificadas com declividade acentuada, contudo com vertente contrária à direção das chuvas. Nesse caso, não haveria efeito direto da cobertura vegetal sobre a atenuação do potencial erosivo das precipitações. O principal componente relacionado a esse efeito seria a combinação dos fatores físicos, relevo e direção predominante das chuvas.

A Figura 7A ilustra o efeito atenuante da cobertura do solo sobre a energia cinética das chuvas durante o mês de abril de 2012. A precipitação acumulada nesse mês foi de $154,6 \mathrm{~mm}$, com $\mathrm{i}=6,4^{\circ}$, as chuvas vieram de SE $\left(\Omega=140,7^{\circ}\right)$, resultando em $\mathrm{Vr}=12,5 \mathrm{~m} \cdot \mathrm{s}^{-1}$. Com esses parâmetros, a simulação do efeito atenuante da cobertura do solo sobre a energia cinética das chuvas discriminou as classes BAIXA (43\%), MÉDIA (53,3\%) e MUITO ALTA $(3,7 \%)$. Nota-se na Figura 7A que a classe mais frequente do efeito atenuante ocorreu sobre áreas de reservas e agricultura, enquanto que a classe considerada de BAIXA atenuação abrangeu áreas onde as culturas ainda estavam em desenvolvimento. Por fim, as áreas com atenuação ALTA se concentraram em reservas de matas ciliares e faces do terreno contrárias à direção predominante das chuvas. 

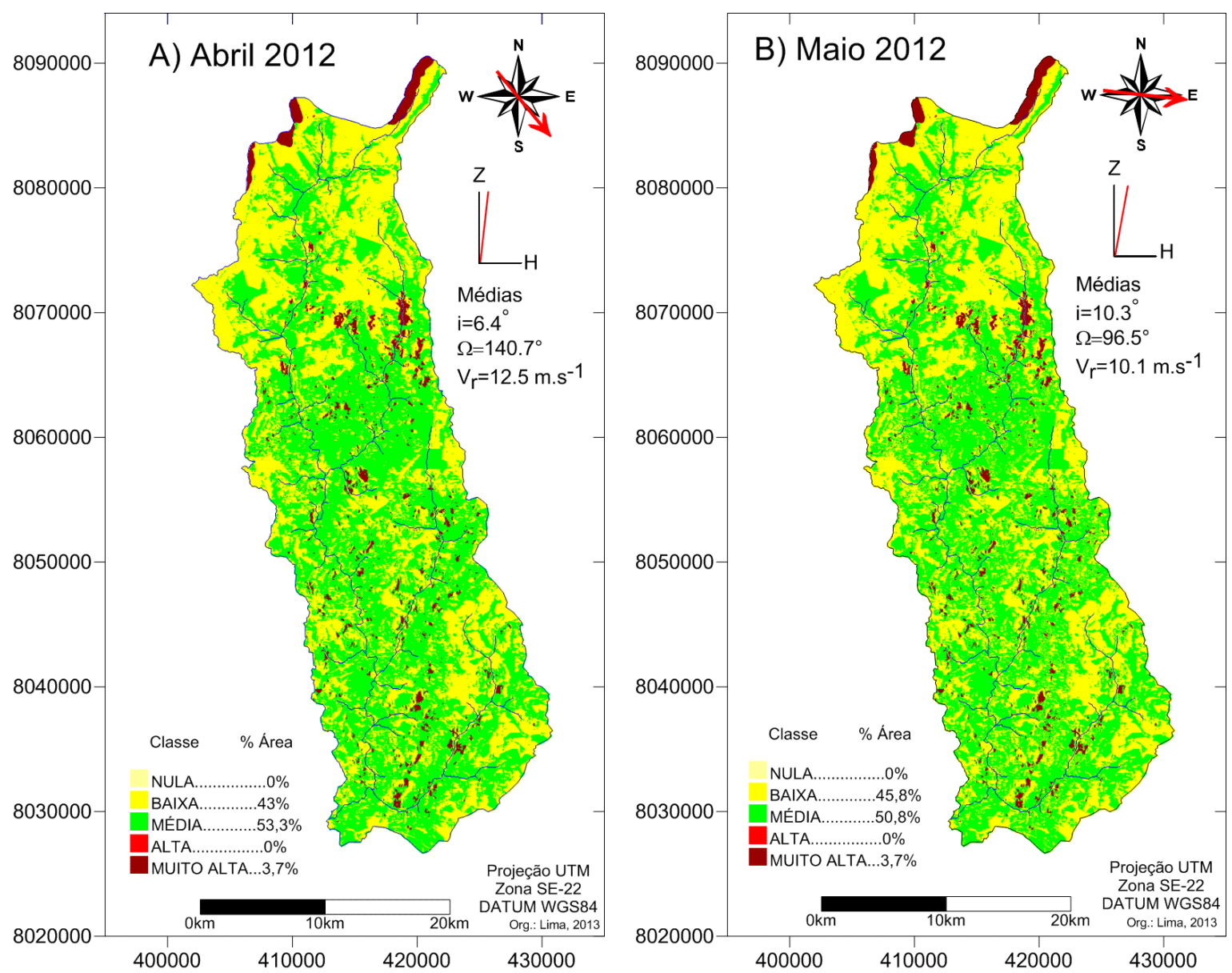

Figura 7 - Classes do efeito atenuante (Ef) da cobertura do solo sobre a energia cinética das chuvas simulada para a bacia hidrográfica do Ribeirão Paraíso (Município de Jataí, Goiás): A) mês de abril/2012; B) mês de maio/2012. Em que: i é a inclinação média; $\Omega$ é a direção; e $V r$ é a velocidade terminal da chuva.

O efeito atenuante da cobertura do solo sobre a energia cinética das chuvas durante o mês de maio de 2012 é ilustrado na Figura 7B. A precipitação acumulada nesse mês foi de $47,4 \mathrm{~mm}$, com i de $10,3^{\circ}$, predominantemente vindas de $E\left(\Omega=96,5^{\circ}\right)$, resultando em $\operatorname{Vr}$ de $10,1 \mathrm{~m} \cdot \mathrm{s}^{-1}$. Com esses parâmetros, a simulação do efeito atenuante da cobertura do solo sobre a energia cinética das chuvas discriminou as classes BAIXA (45,8\%), MÉDIA $(50,8 \%)$ e MUITO ALTA $(3,7 \%)$. Nota-se na figura 7B que a classe mais frequente do efeito atenuante ocorreu sobre áreas de reservas, campos abertos e pastagens, enquanto que a classe considerada de BAIXA atenuação ocorreu em áreas de agricultura, já indicando o período final da safrinha, momento em que a cobertura do solo é reduzida devido à senescência da cultura. As áreas com classe de atenuação ALTA se concentraram em reservas de matas ciliares e faces do terreno com topografia acidentada e contrárias à direção predominante da chuva. 
Durante os meses de safrinha a precipitação acumulada foi de $669,8 \mathrm{~mm}$ de chuva (Erro! Fonte de referência não encontrada.), percebe-se que as maiores reduções de impactos cinéticos foram nos meses de fevereiro com média de 45,1 MJ.ha-1 e março com média de $59 \mathrm{MJ}^{-h a^{-1}}$ de redução, (Erro! Fonte de referência não encontrada.), nos outros dois meses houve reduções proporcionalmente menores, torna-se importante ressaltar que nestes períodos os solos estão cobertos pelas lavouras, o que minimiza o efeito da erosão justamente nas áreas mais afetadas pelo impacto das chuvas.

\subsection{EFEITO ATENUANTE DA COBERTURA DO SOLO SOBRE A ENERGIA CINÉTICA SIMULADA - SAFRA 2012/2013}

A Figura 8A ilustra o efeito atenuante da cobertura do solo sobre a energia cinética das chuvas durante o mês de outubro de 2012. A precipitação acumulada neste mês foi de $115,3 \mathrm{~mm}$ de chuvas, com $\mathrm{i}=11,6^{\circ}$, predominantemente vindas de SW ( $\square \square \square \square \square \square \square \square$ ), resultando em $\mathrm{Vr}=15,8$ m.s-1. Com estes parâmetros, a simulação do efeito atenuante da cobertura do solo sobre a energia cinética das chuvas discriminou as classes MÉDIA $(3,7 \%)$, ALTA $(53,3 \%)$ e MUITO ALTA (43\%). Nota-se na Figura 8 A que a classe mais frequente do efeito atenuante ocorreu em áreas de reservas, pastagens e agricultura. Como nesse mês as chuvas mudaram de direção, essas exerceram impacto de forma diferente sobre a área. Assim, áreas com MÉDIA atenuação provavelmente estavam com a orientação das vertentes voltadas para a direção das chuvas. Finalmente, ocorreu atenuação MUITO ALTA principalmente em áreas de agricultura. 

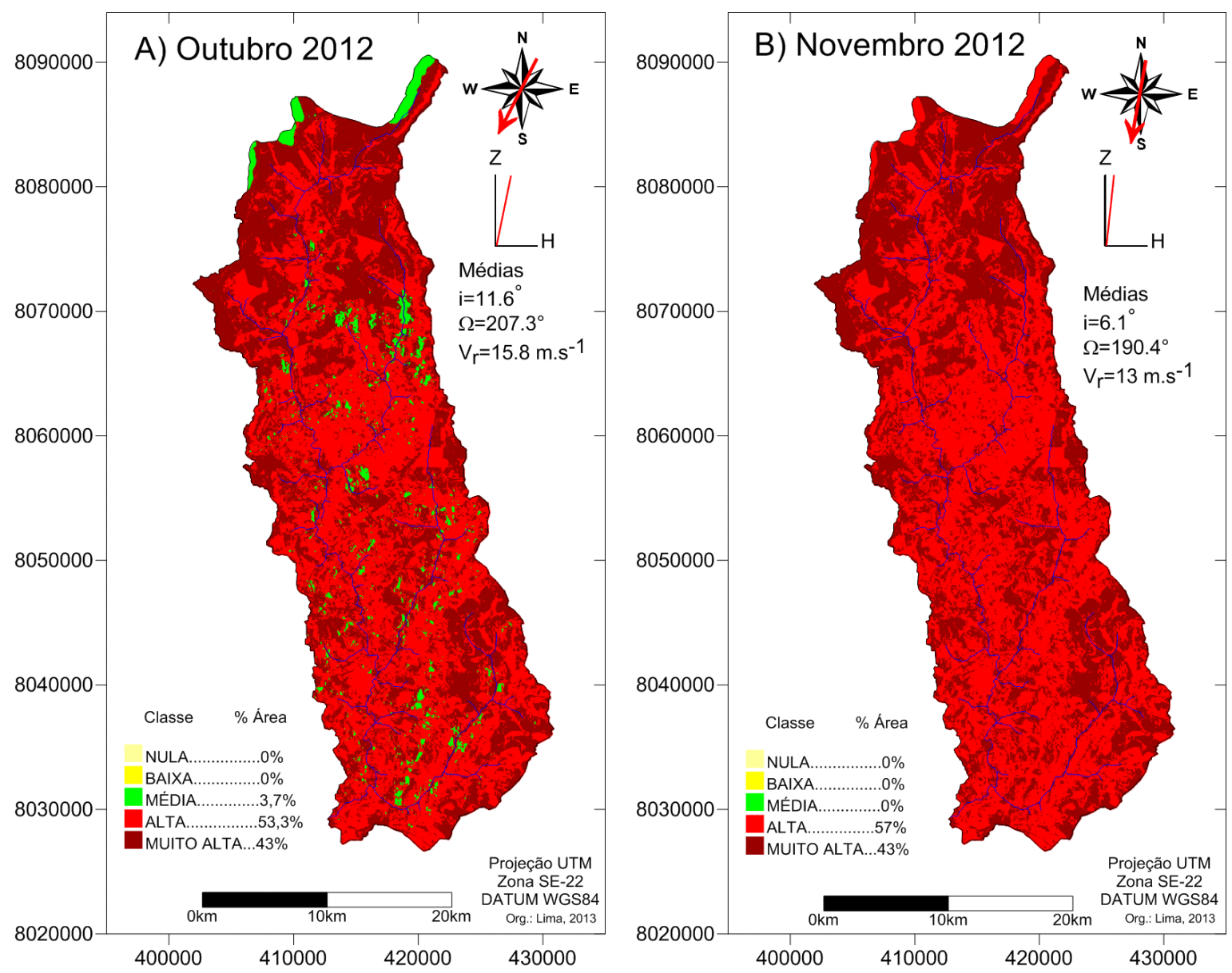

Figura 8 - Classes do efeito atenuante (Ef) da cobertura do solo sobre a energia cinética das chuvas simulada para a bacia hidrográfica do Ribeirão Paraíso (Município de Jataí, Goiás): A) mês de outubro/2012; B) mês de novembro/2012. Em que: i é a inclinação média; $\Omega$ é a direção; e $V r$ é a velocidade terminal da chuva.

A Figura 8B ilustra o efeito atenuante da cobertura do solo sobre a energia cinética das chuvas durante o mês de novembro de 2012. A precipitação acumulada foi de $225,7 \mathrm{~mm}$ de chuva, predominantemente vindas do S $\left(\Omega=190,4^{\circ}\right)$, a inclinação média das chuvas foi de $6,1^{\circ}$, resultando em velocidade terminal da chuva de $13 \mathrm{~m} \cdot \mathrm{s}^{-1}$. Com esses parâmetros, a simulação do efeito atenuante da cobertura do solo sobre a energia cinética das chuvas distinguiu as classes ALTA (57\%) e MUITO ALTA (43\%). Nota-se na Figura $8 B$ que a classe mais frequente do efeito atenuante ocorreu sobre as vertentes e fundos de vales, dominados por reservas, pastagens e agricultura. Enquanto que a classe MUITO ALTA ocorreu sobre as chapadas dominadas pela agricultura, dentro da área da bacia hidrográfica do Ribeirão Paraíso.

A Figura 9A demonstra o efeito atenuante da cobertura do solo sobre a energia cinética das chuvas durante o mês de dezembro de 2012. A precipitação acumulada neste mês foi de $126,6 \mathrm{~mm}$ de chuvas, com i de $12^{\circ}$, predominantemente vindas de $S\left(\Omega=183,6^{\circ}\right)$, resultando em $\mathrm{Vr}$ de $7,8 \mathrm{~m} . \mathrm{s}^{-1}$. Com esses parâmetros, a simulação do efeito atenuante da cobertura do solo sobre a energia cinética das chuvas discriminou as classes ALTA $(53,3 \%)$ e 
MUITO ALTA (46,7\%). Nota-se na Figura 9A que a classe mais frequente do efeito atenuante ocorreu em áreas de reservas, pastagens e agricultura. Esses lugares possuem a orientação das vertentes contrárias à direção das chuvas, o que reduz o efeito erosivo das precipitações. Finalmente, ocorreu atenuação MUITO ALTA principalmente em áreas de agricultura.
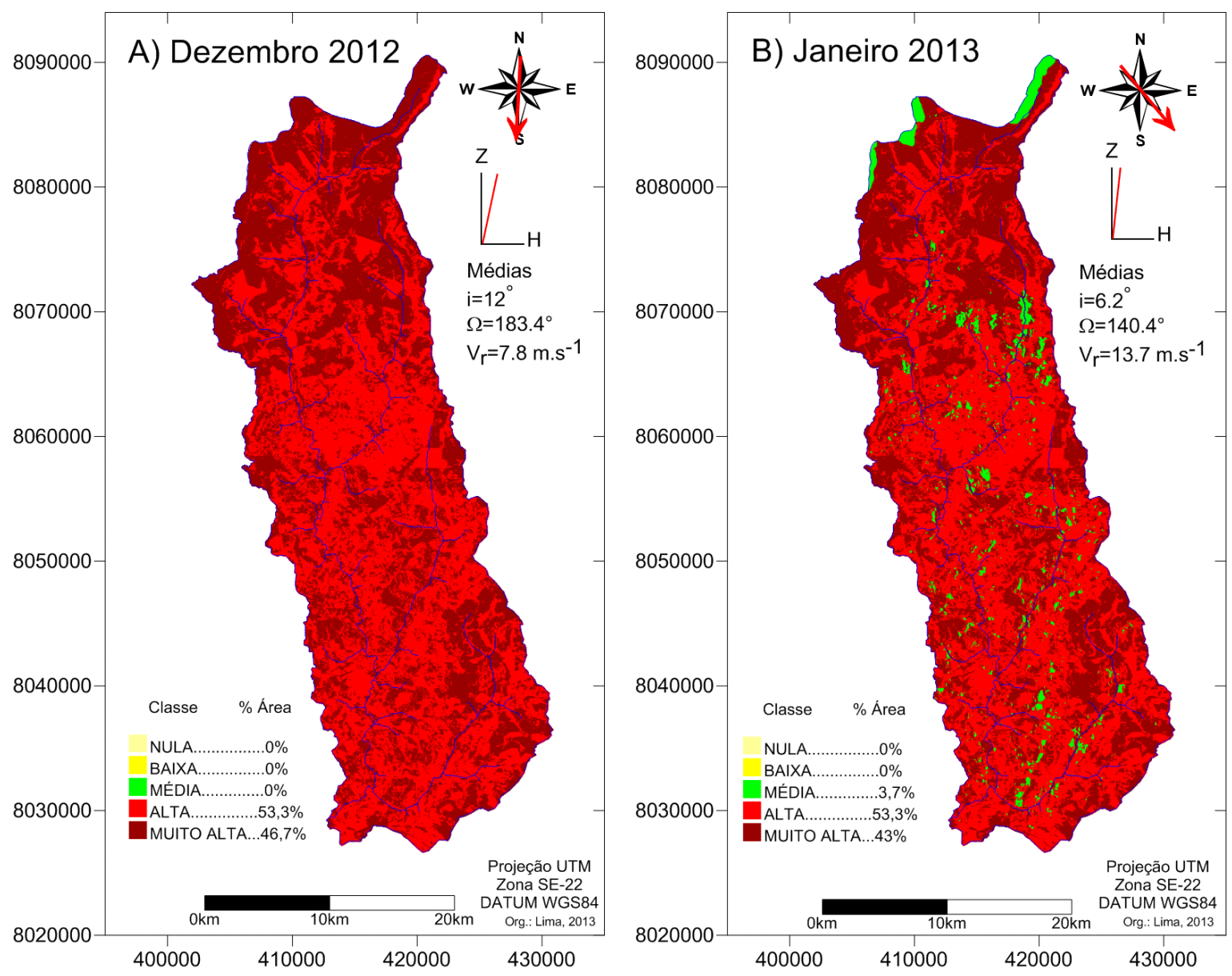

Figura 9 - Classes do efeito atenuante (Ef) da cobertura do solo sobre a energia cinética das chuvas simulada para a bacia hidrográfica do Ribeirão Paraíso (Município de Jataí, Goiás): A) mês de dezembro/2012; B) mês de janeiro/2013. Em que: i é a inclinação média; $\Omega$ é a direção; e $V r$ é a velocidade terminal da chuva.

Na Figura 9B é ilustrado o efeito atenuante da cobertura do solo sobre a energia cinética das chuvas durante o mês de janeiro de 2013. A precipitação acumulada neste mês foi de $252,6 \mathrm{~mm}$, com $i=6,2^{\circ}$, predominantemente vinda de SE $\left(\Omega=140,4^{\circ}\right)$, resultando em $\operatorname{Vr}$ de 13,7 m.s ${ }^{-1}$. Com esses parâmetros, a simulação do efeito atenuante da cobertura do solo sobre a energia cinética das chuvas discriminou as classes MÉDIA (3,7\%), ALTA $(53,3 \%)$ e MUITO ALTA $(43 \%)$. Nota-se na Figura 9B que a classe mais frequente do efeito atenuante ocorreu sobre áreas de reservas e agricultura. Áreas agrícolas situadas em chapadas com topografia plana foram aquelas classificadas como as de 
atenuação MUITO ALTA. Ao passo que a classe considerada de BAIXA atenuação ocorreu em áreas de encostas onde a vegetação é menos densa.

\section{CONCLUSÕES}

Os dados medidos pelos pluviômetros de PVC de $163 \mathrm{~cm}^{2}$ são compatíveis com aqueles registrados pelo pluviômetro padrão do INMET.

A superfície da bacia hidrográfica do Ribeirão Paraíso possui declividade abaixo de $8 \%$ em $87,1 \%$ de sua área, distribuída sobre uma rampa norte-sul de aproximadamente $62 \mathrm{~km}$, entre a nascente e a foz.

A orientação das vertentes tem distribuição uniforme, a maior parte da bacia do Ribeirão Paraíso tem relevo plano a suave ondulado, com algumas partes escarpadas, nas transições entre os chapadões e áreas mais baixas de nascentes.

A atenuação do impacto cinético da chuva para os meses de safra e safrinha na bacia do Ribeirão Paraíso no município de Jataí, mostram que as chuvas possuem inclinações médias entre $6,1^{\circ}$ e $11,6^{\circ}$ e penetram no município pelos quadrantes SE e S.

Para os meses de safrinha as maiores atenuações de impactos cinéticos foram fevereiro, com 31,9\%, e março, com 15,5\% de redução. Para os meses de safra as maiores reduções ocorreram nos meses de novembro, com $64 \%$, e dezembro com $68,2 \%$.

Os maiores impactos concentraram-se nos chapadões e fundos de vale planos, justamente em áreas onde o uso da terra é mais intenso, tornando os solos mais suscetíveis à erosão pelas chuvas.

\section{REFERÊNCIAS BIBLIOGRÁFICAS}

ALLEN, R. G. et al. Crop evapotranspiration: Guidelines for computing crop requirements. Rome. 1998. (0254-5293).

ASSUNÇÃO, H. F. et al. USO DE PLUVIÔMETROS VETORIAIS PARA ESTIMAR A ENERGIA CINÉTICA DAS CHUVAS, 2004. Disponivel em: <http://www.simehgo.sectec.go.gov.br/downloads/publicacoes/artigos/004.pdf >. Acesso em: 11 mar. 2012.

ASSUNÇÃO, H. F. et al. Construção e avaliação de protótipos de pluviômetros vetoriais para estimar o impacto das chuvas sobre encostas. Universidade Federal de Goiás - UFG. Jataí, p. 21. 2011.

ASSUNÇÃO, H. F.; CARNEIRO, M. A. C.; LIMA, V. V. SIMULAÇÃO DA ENERGIA CINÉTICA DAS CHUVAS SOBRE OS SOLOS DE MUNICÍPIO DE JATAÍ-GO. XV CONGRESSO BRASILEIRO DE METEREOLOGIA. São Paulo: A Metereologia e a Cidade. 2008. p. 1-5.

CARVALHO, F. FLUXOS HÍDRICOS NA MICROBACIA DO CÓRREGO DO QUEIXADA NO MUNICÍPIO DE JATAÍ (GO). 2011. ed. JATAÍ: Dissertação (Mestrado em Geografia), v. JATAÍ, 2011.

CHRISTOFOLETTI, A. Geomorfologia. 2a. ed. São Paulo: Edgard Blucher, 1980. 
EITEN, G. Vegetação do Cerrado. In: NOVAES PINTO, M. Cerrado: caracterização, ocupação e perspectivas. Brasília: Universidade de Brasília, 1993. p. 17-73.

EMBRAPA. Centro Nacional de Pesquisa de Solos - Sistema brasileiro de classificação de solos. 2a. ed. Rio de Janeiro: EMBRAPA-SPI, 2006.

FERREIRA, I. M. M.; FERREIRA, A. J. R.; SIMS, D. A. USLE adapted for use in Portugal. Land and Water (FAO), v. 22, p. 21-24, April 1985.

FERREIRA, N. C.; FERREIRA, M. E.; LOBO, F. C. RISCOS DE DESMATAMENTOS E POTENCIAL DE REGENERAÇÃO DA VEGETAÇÃO NATIVA: DEFININDO PRIORIDADES E ESTRATÉGIAS TERRITORIAIS. Boletim Goiano de Geografia, Goiânia, v. 27, n. Especial, p. 83-96, 2007. ISSN 0101708X.

GUERRA, A. J. T. et al. Um Estudo do meio físico com fins de aplicação ao planejamento do uso agrícola da terra no sudoeste de Goiás. 1a. ed. Rio de Janeiro: IBGE, Departamento de Recursos Naturais e Estudos Ambientais, 1989.

GUO, J. C. Y.; URBONAS, B.; STEWART, K. Rain catch under wind and vegetal cover effects. ASCE J. of Hydrologic Engineering, v. 6, n. 1, p. 1-9, 2001.

IMB. Instituto Mauro Borges de estaísticas e estudos socioeconômicos. Seplan, 2006.

em: <http://www.seplan.go.gov.br/sepin/perfilweb/Estatistica_bde.asp>.

Acesso em: 17 dez. 2013.

INMET. Instituto Nacional de Metereologia. Normais Climatológicas do Brasil 1961-1990, 2013. Disponivel em: <http://www.inmet.gov.br/portal/index.php?r=clima/normaisClimatologicas>. Acesso em: 6 Julho 2013.

LIMA, J. L. M. P. The influence of the angle incidence of the rainfall on the overland flow process. 1989. Baltimore: AHS Publ. 1989. p. 73-82.

MOORE, I. D.; LEWIS, A.; GALLANT, J. C. Terrain porperties: Estimation Methods and Scale Effects, Modeling Change in Environmental Systems. New York: John Wiley and Sons, 1993.

NIMER, E. Climatologia do Brasil. 2a. ed. Rio de Janeiro: IBGE, v. II, 1989.

RADAMBRASIL. Geologia, geomorfologia, pedologia, vegetação e uso potencial da terra. Ministério das Minas e Energia. Rio de Janeiro. 1983.

RIZZINI, C. T. Tratado de fitogeografia do Brasil: aspectos ecológicos. São Paulo: Hucitec / Edusp, v. 2, 1979.

SILVA JÚNIOR, U. P. D. et al. PARTIÇÕES PLUVIOMÉTRICAS NOS CULTIVOS DE SOJA, MILHO E BRAQUIÁRIA NO MUNICÍPIO DE JATAÍ (GO). Universidade Federal de Goiás - Campus Jataí. Jataí, p. 85. 2013.

SURFER 11. User's guide - Kriging. Golden Software, Inc. [S.I.]. 2013. 